\title{
Green Corridors as a response for nature: greening Alexandria city by creating a green infrastructure network
}

\author{
S. S. A. Aly \& M. S. E. Amer \\ Architectural Engineering and Environmental Design Department, \\ Arab Academy for Science, Technology and Maritime Transport, Egypt
}

\begin{abstract}
Green Corridors are an essential component of the cities' ecological networks; they are a strong response to environmental problems. They have a dual purpose. In addition to their ecological role in creating a pure vision, and helping people to live in better communities, they provide access routes, and improve the quality of life, particularly social life. Therefore, they should be viewed as part of the overall network of habitats throughout the city.

Green Corridors' designs produce a subsidiary network of greenways to actualize and complete the green infrastructure framework. Alexandria city, Egypt, has many of those corridors, which give a good opportunity to create local Green Networks of high quality. The development of Mahmoudeya Canal, which is the main Green Corridor in Alexandria, may be the main axis to increase the number of open spaces, and to create an attractive urban environment.

This paper aims to apply such corridors to unify and actively connect all parts within the city's fabric and beyond. This will create new channels for population-distribution, provide more economic opportunities and increase the potential value of land potential. It will also present a conceptual design for a Green Network inside the urban form of Alexandria city. Main nodes at the existing canal will be created as the central pivots to run the Green Network into the different parts of the city, and form many areas encircled by greenways. Thus, it will ease the development procedures of these areas to have adaptive green areas and enhance their environmental context.

The paper concludes that Green Corridors have a pivotal role in increasing environmental quality, so planners and decisions makers should incorporate
\end{abstract}


Green Networks in the urban form of the new communities, and plan to develop the existing corridors through good management and maintenance.

Keywords: Green Corridors, ecological network, greenways, green infrastructure.

\section{Introduction}

Urban areas are great magnets to most people; consequently, the rate of people has proliferated in a way that has strained the urban areas, where more job opportunities, technology, major resources and facilities are available. Thus, population centralization and rapid urbanization are correlated with crucial concerns regarding conservation, due to the changing habitat structure and environmental decay (Shochat et al [1]). Urban areas have become the major consumer of natural resources and the largest producer of pollution and waste, which is what has happened in Alexandria city, Egypt. In addition to the city acting as a magnet as an urban area, it also attracts mostly Egyptians from other cities due to its spatial features and coastal aspects. Gradually, urban areas have caused fragmentation of nature by isolating habitats and species, which should be connected (Jongman and Pungetti [2]). In this context, the continuance of these problems will interrupt and reduce sustainability in the urban areas of Alexandria city.

The aim of this study is to balance the equation between "reducing urban sustainability" and "achieving urban sustainability". Wherefore, and to achieve urban sustainability, greening Alexandria city became an important issue. This paper explains the importance of Green Corridors, which have become an important planning tool in urban sustainability; the goal of this study is to employ this tool. Systematically, it will identify the opportunities of Alexandria city to have a Green Network and present a vision of a theoretical scheme for this network, depending on its available natural resources, which is the skeletal framework of the proposed comprehensive plan scheme of the city's Green Network. This vision aims to achieve four main objectives: (a) maintain and improve environmental quality through nature protection, (b) increase economic development through appropriate tourist activities, recreation development and historic conservation, (c) create high land value potential through having a welldistributed population, (d) create a dynamic network to provide sustainable transportation through walking and finding the right of use of riding, cycling, and light motorized transportation.

The methodology of this study is constructed as follows. (1) Reviewing the theoretical studies in nature conservation, and Green Network planning to conclude the applied concept. (2) Studying the probability of forming the Green Network framework through the inventory of available nature corridors in the city. (3) Applying the concluded concept in Alexandria city, and planning a new proposal depending on the development of these resources to complete the comprehensive scheme of the Green Network. (4) Specialized study to develop many connectivity nodes on the Mahmoudeya Canal to establish its potential applications in all of the important inventoried arteries and complete the conceptual design of the greening the city. 


\section{Literature review}

Green Corridors and Greenways are two concepts that are often treated effectively as one; both focus on the provision of opportunities and linear routes with a wide range of characteristics and uses (Vasconcelos et al [3]). The potential Green Corridors will serve multiple purposes, with a stronger emphasis on particular goals, depending on where they are located.

\subsection{Definitions, types and functions}

Numerous definitions of greenways have been given, according to their purposes and scale, as follows: urban riversides, recreational trails, ecologically significant natural corridors, and scenic or historic routes (Little [4]). All of these types can produce a comprehensive greenways network. According to Fabos' description (1995), greenways can be corridors of various widths, linked together in a network with significant characterization of ecologically, recreational, cultural and historical features (Shafer et al [5]). Greenways are linear elements; they can connect parks, nature reserves and cultural and historical sites to other protected lands (Jongman and Pungetti [2]). They are all linear open spaces; they include coastal areas, riparian corridors, town paths along canals and riverbanks, recreational corridors, utilitarian corridors, cycle ways, rights of way and disused railway lines. Those types of greenways have the primary purpose of providing opportunities for walking, cycling and riding horses, whether for leisure or travel purposes and opportunities for wildlife migration (Jongman and Pungetti [2]). In a few words; they can be identified as having five key ideas within this definition: (1) a linear configuration, (2) linkage, (3) multi functionality, (4) consistency with sustainability, (5) integration.

Functionally, Green Corridors increase in value if they are linked to form a Green Network that extends and takes the initiative to create the city's green infrastructure framework. An important function of environmental corridors appears when they are expressed in ecological, physical and cultural terms by using it as the basis for the community heritage. The evidencing of that appears in Wisconsin, USA, where more than $90 \%$ of recreational, cultural, and historic resources were found and occurred along Wisconsin corridors (Jongman and Pungetti [2]). So, the Green Networks should be designed and managed for multiple purposes including (a) ecological, (b) recreational, (c) cultural, (d) aesthetic, or (e) other purposes compatible with the concept of sustainable land use.

\subsection{Benefits of Green Corridors in urban sustainability}

When Green Corridors produce a Green Network, it helps to reconnect people with nature, so they provide immediate benefits for people, and extend the effectiveness of these benefits to communities.

Ecologically, Green Corridors include high quality habitats and ecosystems, especially the natural corridors such as riparian corridors, waterways and aquatic habitats (Hellmund and Smith [6]). They prevent soil erosion and they absorb 
rainwater, thereby improving drainage, and protect against the urban heat island effect (Wilkie and Roach [7]). The diversity of activities through them ameliorates the ecological consequences, such as greening urban areas, agriculture, forestry, and recreation facilities (Hellmund and Smith [6]). Finally, Green Corridors and their inhabitants are good indicators of the overall ecological health of the ecosystem (Wilkie and Roach [7]).

Socially, Green Corridors have recreational uses: a place to play, meditate, gather, or rest. They give people the sense of place, of identity and of belonging, and enhance feelings of family kinship and solidarity. They provide the opportunity to reflect on personal and social values, promote culture and spiritual growth, and increase the sense of community. In general, Green Corridors allow users to feel free in a more structured environment (Wilkie and Roach [7]).

Environmentally, Green Corridors provide a high quality life through integrating nature into the urban environment and stimulating the senses with their simple colour, sound, smell, and motions. They play an important role in reshaping the urban spatial pattern and establishing connectivity for a wide variety context across the city (Wilkie and Roach [7]). Loops and intersections produce a variety of routes and greenways that help to increase accessibility and forming or transforming the city form by delimiting its land use (Hellmund and Smith [6]).

The main function of each corridor as a natural environment corridor is sustainable transportation. A dynamic greenway network can form an important part of a sustainable transport system. Therefore, it works as the channel distribution of population and activities (Tuner [8]).

Regarding these benefits, Green Corridors are a sensitive response towards urban sustainability. In other words, Green Corridors are a crucial planning tool in implementing urban sustainability.

\section{Ecological network}

An ecological network is defined as the conservation of nature and a coherent system for the fragmented landscape elements; it can offer more biological diversity for core areas with its interconnections by buffer zones and ecological corridors.

A new concept and theory have to improve these interconnections, detect gaps and provide continuity of connectivity (Jongman and Pungetti [2]).

\subsection{Network components and theory}

Greenways have been inspired from ecological corridors in European nature conservation at different levels; both Greenways and ecological networks are similar in concept and structure, even if they are different in approaches and functions (Jongman and Pungetti [2]). Networks consist of nodes and links that can be used to represent a given system in terms of its localized components; it connects the eco-systems and landscape in a system of hubs, links, and sites, fig.1. 

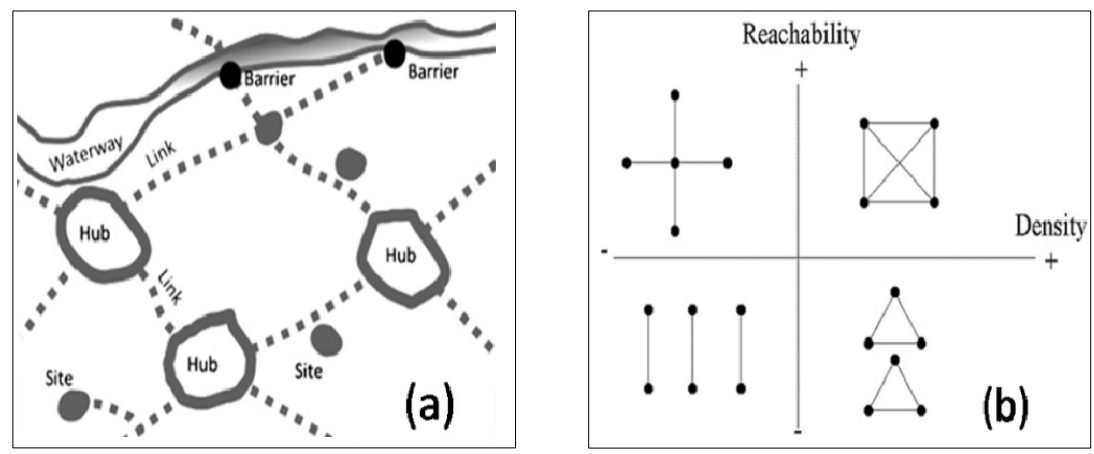

Figure 1: Diagram in figure (a) depicts the connection between network elements (sketched by the author); diagram in figure (b) illustrates the different types of reachability and density (from Janssen et al [10]).

Hubs anchor the green infrastructure network with large reserves and protected areas, such as national wildlife, forest, and state parks. Links are the connections that connect all parts of the system together, such as greenways, greenbelt, rivers, and stream floodplains, that provide space for recreational use or historic sites. In addition, they include sites that are smaller in area than hubs. They may not be attached to the network, but they can present important ecological and social values (Benedict and McMahon [9]). Theories of Green Networks provide designers with suggestions of how they employ the greenways in forming a network system (Hellmund and Smith [6]). Network theories depend on priorities at two levels; level of connectivity and level of centrality as the two main characteristics, fig.1. Connectivity is the density of links within the network; it leads to reachability with the maximum possible number of links and makes all nodes more accessible to each other (Janssen et al [10]).

Level of centrality is the distribution of links among the nodes in a network according to their structural importance or their own benefits, fig. 1 .

For example; some hubs in the network are most likely of higher ranking in importance than others. Nodes do not necessarily need a specific number of links to be of certain importance, because they can connect different clusters, there are some high ranking nodes in the network that have a significantly high ranking through many links far beyond their local network (Janssen et al [10]).

\subsection{Barriers of network connectivity in metropolitan areas}

Green Corridors have an important role as landscape connectors: they connect, protect, and enhance ecological, recreational, and cultural resources. They may include conservation corridors without recreation access; they have a slightly different focus for implying ecological infrastructure networks, but they help in forming them (Jongman and Pungetti [2]). The linkage of stand-alone corridors into a regional infrastructure network will include new spatial forms besides 
enhancing the existing resources, so their implementation is very difficult and has many barriers, especially through metropolitan areas. Therefore, some attention should be given in the planning and implementation process, such as economic impacts, historic precedents, citizens' mobilization, typologies, natural or topographic barriers, land acquisition, and conflict resolution (Jongman and Pungetti [2]). These barriers have a negative effect; urban areas and their fabric have pronounced ecological effects in blocking connectivity; isolation and fragmentation is caused by linear structures, such as roads, and urban coastal areas, fig.2.
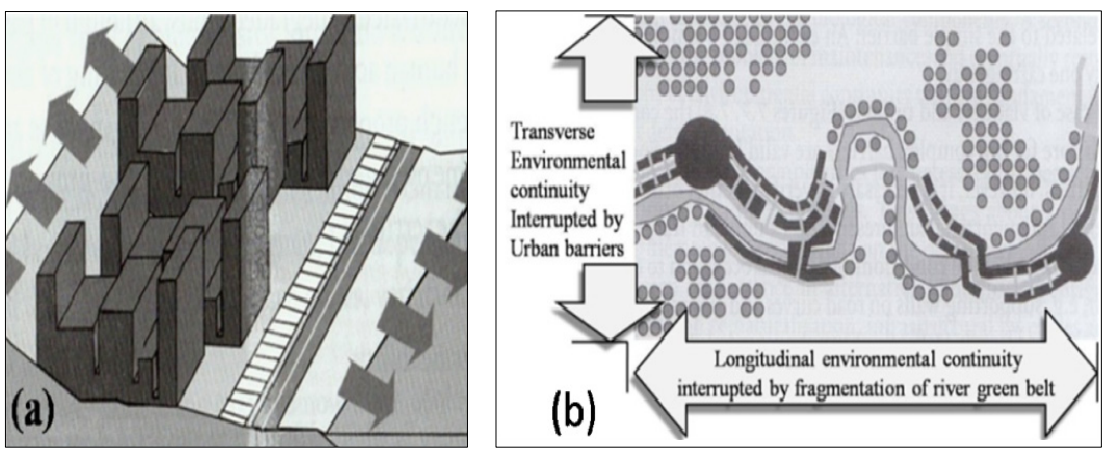

Figure 2: The fragmentation in (a) is caused by a coastal urban area, (b) depicts the effects of linear urbanization on an environmental continuity in a valley, from Jongman and Pungetti [2].

Environmental continuity in linear structures may be found in nature areas by containing activities, recreation, and human impact to be adapted with the urban environment. Some natural linear barriers have connectivity in their form, such as rivers, canals, and continuous green areas (Jongman and Pungetti [2]). The evaluation of each barrier could be limited to the use of crossing pathways, tunnels, and viaducts as a continuity solution according to its physical statement.

\section{Conceptual design for a Green Network in Alexandria city}

The application of a Green Network in Alexandria city needs to take into account the network theory, concept and elements mentioned previously. This part of the study achieves the required aim; it consists of two parts as follows. (a) Presenting a conceptual design for the Alexandria Green Network through definition of its opportunities. (b) Presenting a detailed study to develop one of those opportunities; creating and designing high priority nodes along the Mahmoudeya Canal will be carried out to implement the proposed network. 


\subsection{City profile, urban growth direction and the need for a Green Network}

Alexandria city is located on the Mediterranean Sea as the chief port of Egypt and has a population of 3.9 million inhabitants; Alexandria has acquired a unique place in history as a cosmopolitan city and a cultural landmark (Cities Alliance [11]). Alexandria is formed as a T-shaped peninsula and a strip of land delineated by the Mediterranean Sea and Lake Maryout, fig.3.

Alexandria's urban growth is expected to persist to the edges of the current urban extent; this can be detected in the western, the southern and the southeastern directions (Abdou Aziz [12]). The direction of urban growth to the southeastern parts is a serious threat to the cultivated land, which already experiences continuous loss, fig. 4 .
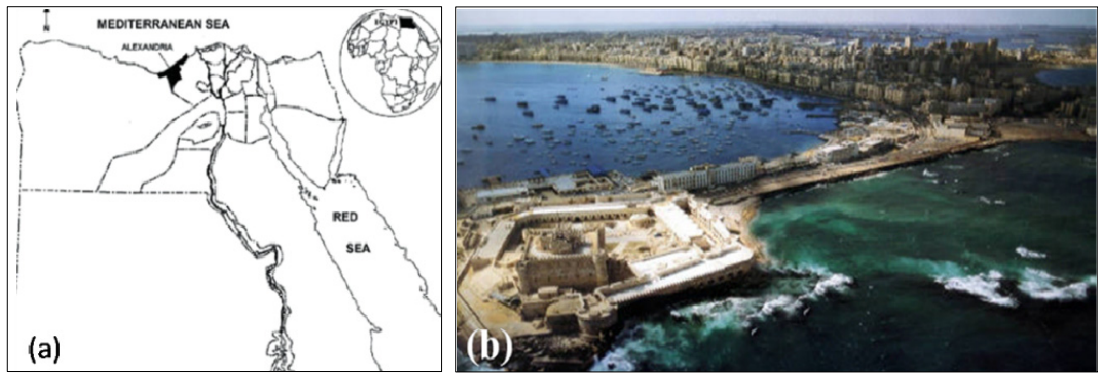

Figure 3: The location of Alexandria city (a), from Abdou Aziz [12]. An overview photo for Alexandria metropolitan area (b), from documentation of Alexandria city, 2004-2007 (Cities Alliance [11]).
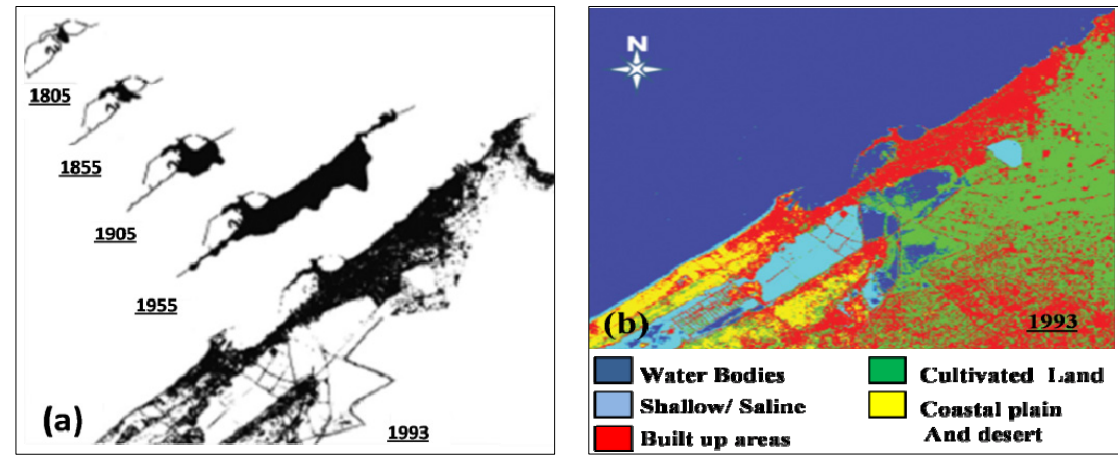

Figure 4: $\quad$ Physical expansion of Alexandria during the $19^{\text {th }}$ and 20 th centuries (a); Alexandria land categories in 1993 (b), built up areas appear in red. The expected urban growth of Alexandria in 2055 will overfill the cultivated land that appears in green (from Abdou Aziz [12]) (colour online only). 


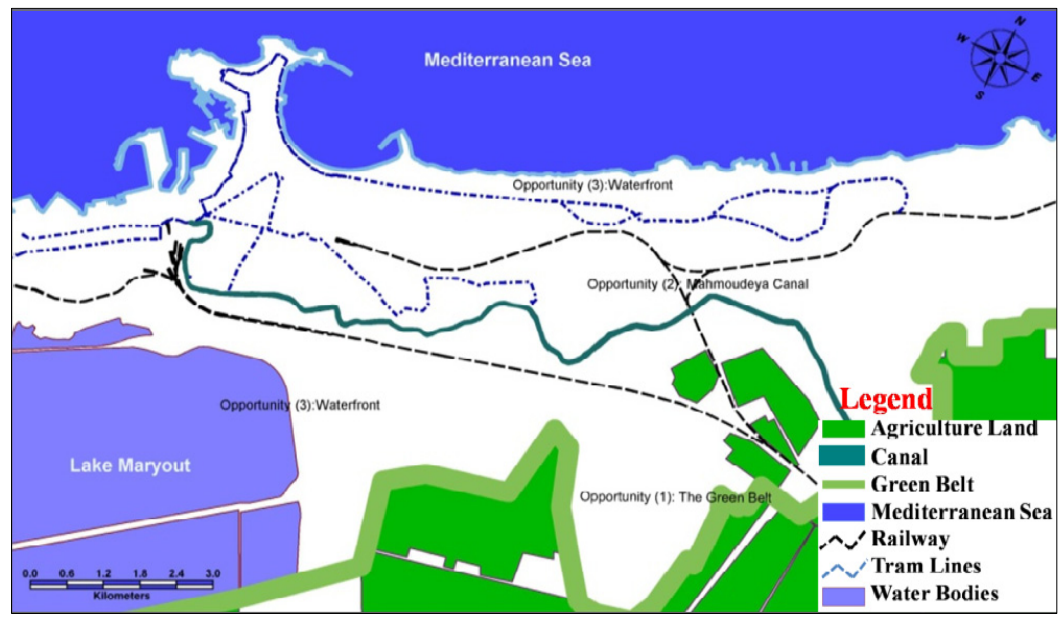

Figure 5: The opportunities of Alexandria city to have a Green Network.

The annual rate of loss for green land is $0.67 \%$ according to Abdou Aziz [12]. If this rate continues, the area of green lands will face the risk of reducing by about $75 \%$ by 2096, fig.4 (Abdou Aziz [12]). To protect the valuable green lands from this continuous risk, strong policies need to be accompanied by rethinking in profiteering the available natural resources and corridors to form the Green Network, which guides the city's growth towards a suitable urban development.

\subsection{Development opportunities: "A Green Network"}

Alexandria city has many opportunities to have a well planned Green Network by the development of its components and concept. Three Canadian case studies in Ottawa, Meewasin and Toronto are similar in their natural elements to the available resources in Alexandria, so they are a good guidance in profiteering the opportunities of Alexandria city to have a Green Network within its urban fabric. The cultivated land around the city could be a greenbelt that offers one of these opportunities; Mahmoudeya Canal and the waterfronts of Lake Maryout and the Mediterranean Sea offer the other opportunities, fig.5.

\subsubsection{Opportunity (1): from greenbelt to a Green Network}

The city of Alexandria is encompassed by cultivated lands in the south-eastern direction that form a greenbelt; this can be developed to be similar to the Ebenezer Howard concept. The greenbelt will be intended to prevent further urban sprawl and to protect adjacent agricultural land from being deteriorated. From the exemplification of the greenways network in Ottawa, Canada, the Alexandria Green Network could be implemented from the concept of city greenbelt. From the outset in Ottawa, the greenbelt was intended to incorporate a variety of land uses within its boundaries, including natural areas, recreation facilities, farmland and land held in reserve to meet future needs. A system of 
trails and scenic driveways were proposed to provide access from the greenbelt to other urban and rural transportation routes (Taylor et al [13]).

\subsubsection{Opportunity (2): from a waterway to a Green Network}

The city of Alexandria includes the Mahmoudeya Canal as an important natural corridor, which interpenetrates the eastern city's fabric. During the 19th century, and through Muhammad Ali's efforts to modernize Egypt as a whole, he established Mahmoudeya Canal as a means to provide the city with fresh water and also as a waterway connection with the Nile River by giving direct access to and from the Nile at Cairo, fig. 6.

With the completion of Mahmoudeya Canal in 1820, Alexandria became the major centre of population and economic growth between all Egyptian governorates (Egypt State information service [14]).

From the exemplification of the greenways network in Meewasin Valley, Canada, the Alexandria Green Network could be implemented from the concept of a city waterway. The conceptual ideas of Meewasin greenways were to be realized through the development of eight nodes located along the length of the valley. The nodes in the metropolitan area were identified for the development of cultural, commercial and business facilities, as well as recreational uses. Between all of these nodes a system of greenways was implemented, this system makes it possible to walk, hike, cycle or ski between all the nodes (Taylor et al [13]).

\subsubsection{Opportunity (3): from a waterfront to a Green Network}

The city of Alexandria is famous for its waterfronts, which are a strip of land delineated by the Mediterranean Sea in the north and Lake Maryout in the western- south direction. The concept of these waterfronts could be developed to form the Alexandria Green Network in the same manner as the greenway development concept of Toronto, Canada. Two-tiered systems are proposed, with arterial greenways that are established to be connected within each

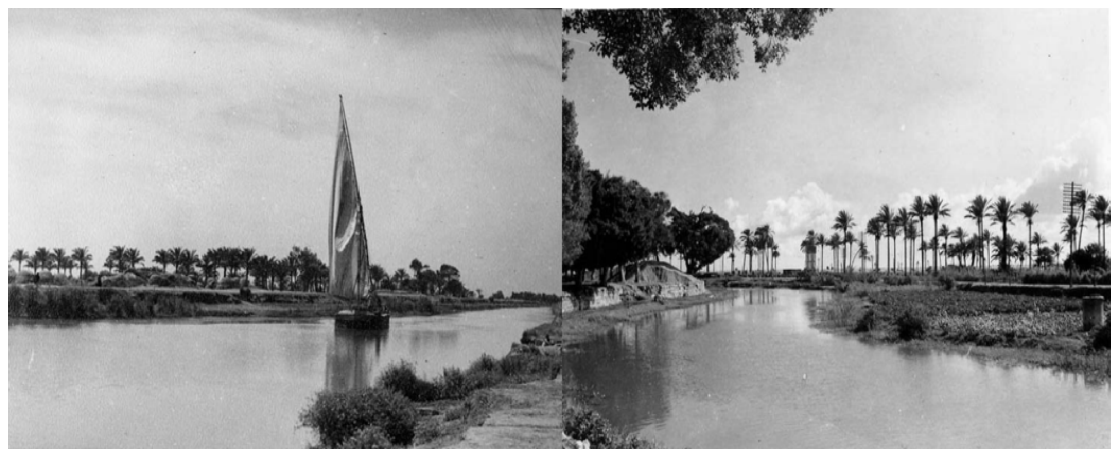

Figure 6: The Mahmoudeya Canal in the 19th century (source: bibliotheca of Alexandria, the private exhibition about the history of Alexandria). 


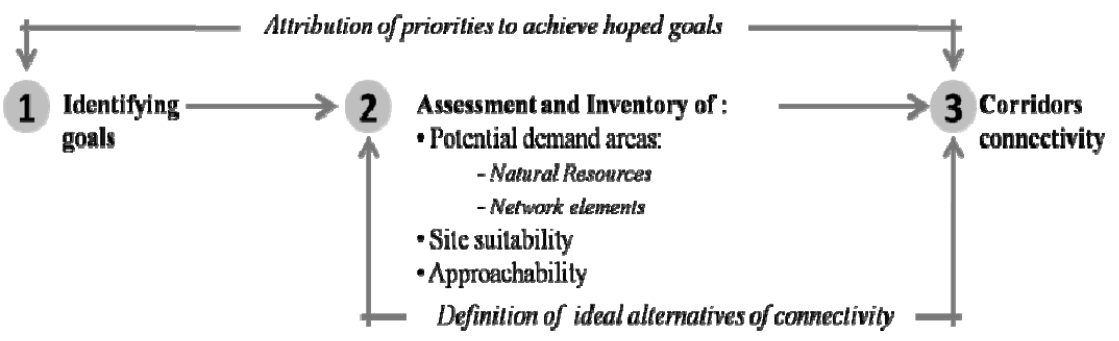

Figure 7: The methodology diagram illustrates the network planning process.

community. One of these arterial systems includes a waterfront trail along the shore of Lake Ontario, and another is a system across the region and local connectors within each community. The local connectors are to be developed according to municipalities' priorities and the availability of potential land. Rail lines and other utility corridors help in improving these connectors to tie community parks and tributary valleys in order to provide many recreational trail loops (Taylor et al [13]).

Each of those opportunities can form a network by its own features and system; while the greenbelt concept will form a biodiversity network and wildlife, waterfronts will form a network for recreation use, and in addition the Mahmoudeya Canal can provide a good ecological network. Grouping and realizing those networks should complete Alexandria's framework into a total system and a network characterized by great diversity, fig.5.

\subsection{The conceptual planning process}

Planning a Green Network in Alexandria should include interrelationships among resources and opportunities as a whole system, not as separate parts; the flow diagram in fig. 7 illustrates the three main steps of the planning process.

\subsubsection{Identification of goals and objectives}

The goals and objectives of the study were outlined as previously mentioned. They are achieved through surveys, and meetings with local residents. It is essentially a "needs assessment", which ascertains the desires and requirements of the communities. These requirements are then incorporated and addressed throughout the planning process, fig.7.

\subsubsection{Assessment and inventory process}

4.3.2.1 Potential demand areas: natural resources and network elements Through this step, areas that demand connectivity should be identified, which are geographically separated locations where certain types of human activities take place. It focuses on: (1) corridors, such as canals and waterfronts; (2) significant green nodes and connections of corridors, such as residential and public squares, alleys, and pedestrian walkways; (3) existing and potential recreational attractions; (4) available public lands and opportunities for securing other high priority areas, such as parks and open spaces; (5) visual corridors that are 


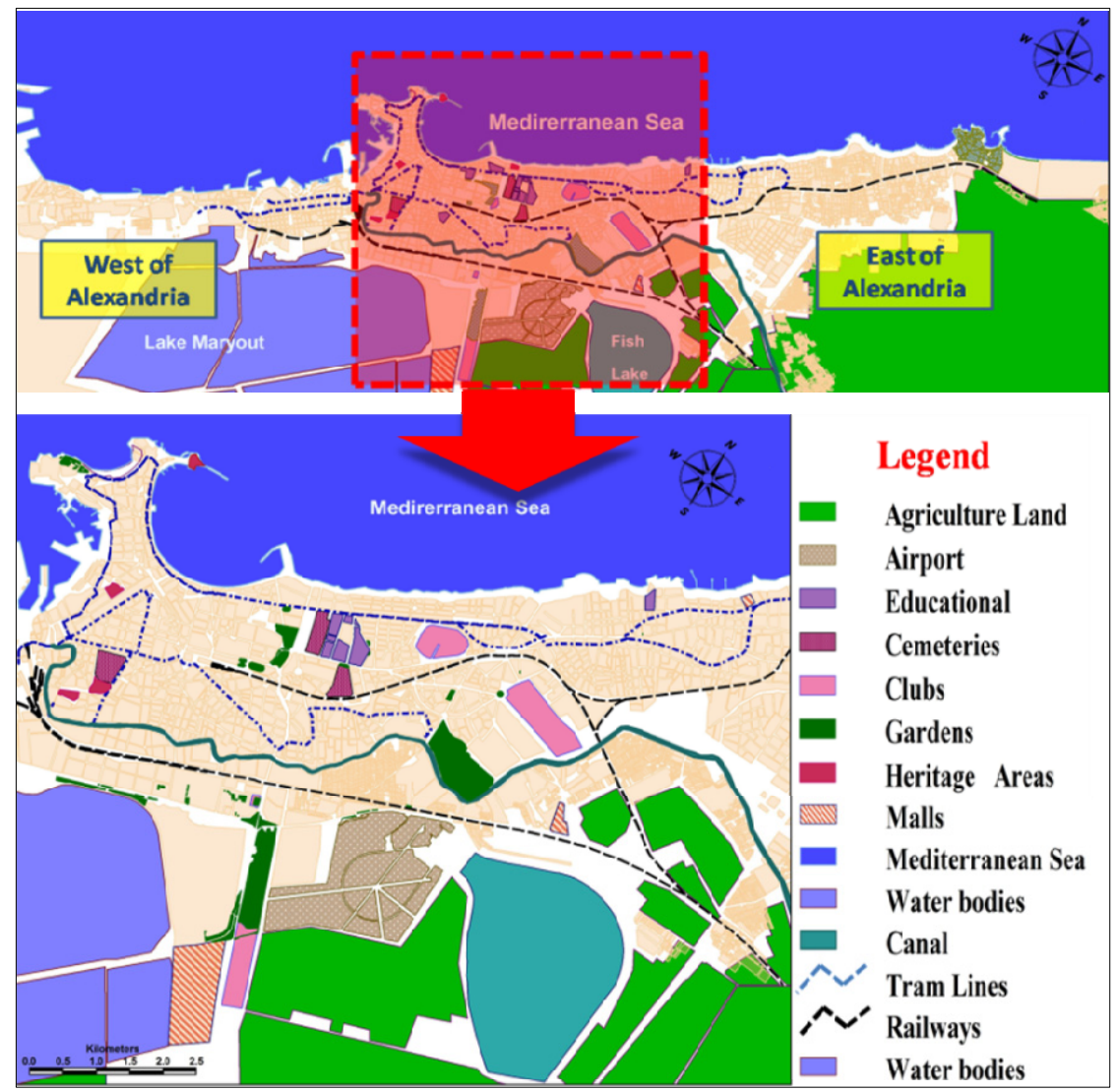

Figure 8: The demand areas centralized in the middle part of Alexandria city. The map shows the result of the inventory process of the existing network elements in the city.

required to be protected for their scenic quality and to provide the community with significant heritage features. The elementary survey showed that the demanded areas that need to be connected are found in the middle part of the city, whereas the eastern and western parts suffer from a lack of important nodes, fig.8.

Extending the Green Network through these parts is needed in order to create new important nodes and hubs through its urban areas, such as green areas, recreational facilities, educational, or services areas.

4.3.2.2 Assessment of site suitability A suitability assessment process is then performed in order to identify areas that are most suitable for being part of a future Green Network. An area's suitability is determined by priority of importance, and the degree of its necessity. Table 1 shows the hypothesis criteria that predicated to define these priorities, fig. 8 . 
Table 1: The priorities classification for inventoried areas, $(* * *)$ indicates high, $(* *)$ indicates medium, and $(*)$ indicates low.

\begin{tabular}{|c|c|c|c|c|c|}
\hline \multicolumn{4}{|c|}{ Area } & \multirow{3}{*}{ 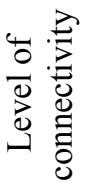 } & \multirow{3}{*}{ 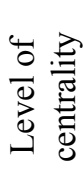 } \\
\hline 8 & \multirow{2}{*}{ Name } & \multicolumn{2}{|c|}{ Coordinates } & & \\
\hline$E$ & & $\mathrm{~N}$ & $\mathrm{E}$ & & \\
\hline \multirow{7}{*}{ 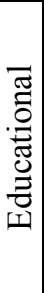 } & Academic colleges & $31^{\circ} 12^{\prime}, 444$ & $29^{\circ} 54^{\prime}, 641$ & $* *$ & $* * *$ \\
\hline & Faculty of medicine & $31^{\circ} 12^{\prime}, 106$ & $29^{\circ} 54^{\prime}, 415$ & $* *$ & $* * *$ \\
\hline & Faculty of engineering & $31^{\circ} 12^{\prime}, 443$ & $29^{\circ} 55^{\prime}, 450$ & $* *$ & $* * *$ \\
\hline & Faculty of science & $31^{\circ} 10^{\prime}, 986$ & $29^{\circ} 54^{\prime}, 878$ & $*$ & $*$ \\
\hline & Practice colleges & $31^{\circ} 12^{\prime}, 362$ & $29^{\circ} 55^{\prime}, 307$ & $* *$ & $* * *$ \\
\hline & Faculty of fine Arts & $31^{\circ} 14^{\prime}, 452$ & $29^{\circ} 57^{\prime}, 704$ & $* * *$ & $* * *$ \\
\hline & Arab academy & $31^{\circ} 18^{\prime}, 568$ & $30^{\circ} 03^{\prime}, 877$ & $* *$ & $* * *$ \\
\hline \multirow{5}{*}{ 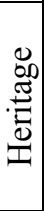 } & The castle & $31^{\circ} 12^{\prime}, 840$ & $29^{\circ} 53^{\prime}, 135$ & $* * *$ & $* * *$ \\
\hline & Abou Elabas area & $31^{\circ} 12^{\prime}, 366$ & $29^{\circ} 52^{\prime}, 932$ & $* * *$ & $* * *$ \\
\hline & City centre & $31^{\circ} 11^{\prime}, 843$ & $29^{\circ} 53^{\prime}, 564$ & $* * *$ & $* * *$ \\
\hline & Kom El Nadora & $31^{\circ} 11^{\prime}, 603$ & $29^{\circ} 53^{\prime}, 283$ & $*$ & $* *$ \\
\hline & Kom El Shukafa & $31^{\circ} 10^{\prime}, 707$ & $29^{\circ} 53^{\prime}, 575$ & $*$ & $* *$ \\
\hline \multirow{5}{*}{$\begin{array}{l}\bar{\pi} \\
.0 \\
00 \\
0 \\
0 \\
0 \\
0 \\
.1\end{array}$} & The zoo & $31^{\circ} 12^{\prime}, 258$ & $29^{\circ} 56^{\prime}, 700$ & $*$ & $* * *$ \\
\hline & Antonyads Park & $31^{\circ} 12^{\prime}, 155$ & $29^{\circ} 57^{\prime}, 013$ & $*$ & $* * *$ \\
\hline & International garden & $31^{\circ} 10^{\prime}, 720$ & $29^{\circ} 55^{\prime}, 797$ & $*$ & $* *$ \\
\hline & Shalalat Garden & $31^{\circ} 12^{\prime}, 162$ & $29^{\circ} 54^{\prime}, 853$ & $* * *$ & $* * *$ \\
\hline & Mamora city beach & $31^{\circ} 17^{\prime}, 427$ & $30^{\circ} 01^{\prime}, 834$ & $* * *$ & $* * *$ \\
\hline \multirow{8}{*}{ 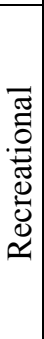 } & Sporting club & $31^{\circ} 12^{\prime}, 920$ & $29^{\circ} 55^{\prime}, 973$ & $* * *$ & $* * *$ \\
\hline & Smouha club & $31^{\circ} 12^{\prime}, 913$ & $29^{\circ} 57^{\prime}, 228$ & $* *$ & $* * *$ \\
\hline & Olympic club & $31^{\circ} 12^{\prime}, 003$ & $29^{\circ} 55^{\prime}, 038$ & $* *$ & $* * *$ \\
\hline & Acacia \& Lagoon & $31^{\circ} 10^{\prime}, 381$ & $29^{\circ} 56^{\prime}, 083$ & $*$ & $* *$ \\
\hline & Montaza palace Park & $31^{\circ} 17^{\prime}, 037$ & $30^{\circ} 00^{\prime}, 968$ & $* * *$ & $* * *$ \\
\hline & Sant Stefano mall & $31^{\circ} 14^{\prime}, 734$ & $29^{\circ} 57^{\prime}, 992$ & $* * *$ & $* * *$ \\
\hline & Carrefour mall & $31^{\circ} 10^{\prime}, 190$ & $29^{\circ} 55^{\prime}, 899$ & $*$ & $* * *$ \\
\hline & Green plaza mall & $31^{\circ} 12^{\prime}, 366$ & $29^{\circ} 57^{\prime}, 919$ & $*$ & $* * *$ \\
\hline \multirow{6}{*}{$\underbrace{0}_{0}$} & Nozha airport & $31^{\circ} 11^{\prime}, 028$ & $29^{\circ} 56^{\prime}, 948$ & $*$ & $* *$ \\
\hline & Alexandria Harbour & $31^{\circ} 11^{\prime}, 738$ & $29^{\circ} 53^{\prime}, 044$ & $* * *$ & $* * *$ \\
\hline & Alexandria railway station & $31^{\circ} 11^{\prime}, 605$ & $29^{\circ} 54^{\prime}, 407$ & $* * *$ & $* * *$ \\
\hline & Sidi-Gabr railway station & $31^{\circ} 13^{\prime}, 147$ & $29^{\circ} 56^{\prime}, 541$ & $* * *$ & $* * *$ \\
\hline & Muhram bik transit area & $31^{\circ} 10^{\prime}, 629$ & $29^{\circ} 54^{\prime}, 900$ & $*$ & $* *$ \\
\hline & Cemeteries & $31^{\circ} 11^{\prime}, 073$ & $29^{\circ} 53^{\prime}, 701$ & $*$ & $* * *$ \\
\hline
\end{tabular}


4.3.2.3 Approachability, assessment of accessibility Although an area might have a high site suitability score, it may not be accessible to potential trail users by the existing transportation infrastructure. The approachability score of an area that is either high or low depends on its accessibility. Table 1 illustrates the ranking of inventoried areas in the city of Alexandria; the classification and prioritization of these areas depends on the output analysis of a Geographic Information System (GIS) and sites surveys and sometimes depend on meetings with stakeholders (the GIS software used here is Geo-Media ${ }^{\circledR}$ professional version 6.1).

\subsubsection{Proposal for the necessary nodes}

The locations of the proposed nodes depend on a site survey for available vacant or unused areas that can become important areas, fig.9.

As previously mentioned, these areas should have good accessibility and enough suitability. The classification of these areas is illustrated and labled as follows.

(1) New project by Alex West on the northern west coast, (2) and (3) land at the Alexandria chemicals factory and Dekhila steel factory that should be removed because of the environmental problems on the adjacent sites, (4) Dekhila harbour, which should be developed to be an attractive tourism harbour, (5) Ras El teen area and fish market area, which should be considered for their traditional and historical values, (6) Lake Maryout, which can be used in the future as an extension for the urban growth of Alexandria, (7) copper factory, which has already been removed and is now vacant land, (8) vacant land on the shore of a fish lake, (9) Sabahy textile factories, which have already been removed, (10) contiguous areas to cultivated land, which include parks and recreation facilities, (11) vacant land along the new artery of the international coastal road, (12) the intended location for new faculties, (13) Abou Kir harbour, which should be developed for multi functions, especially tourism, (14) Nelson island in the Dead Sea, which has a good historical value.

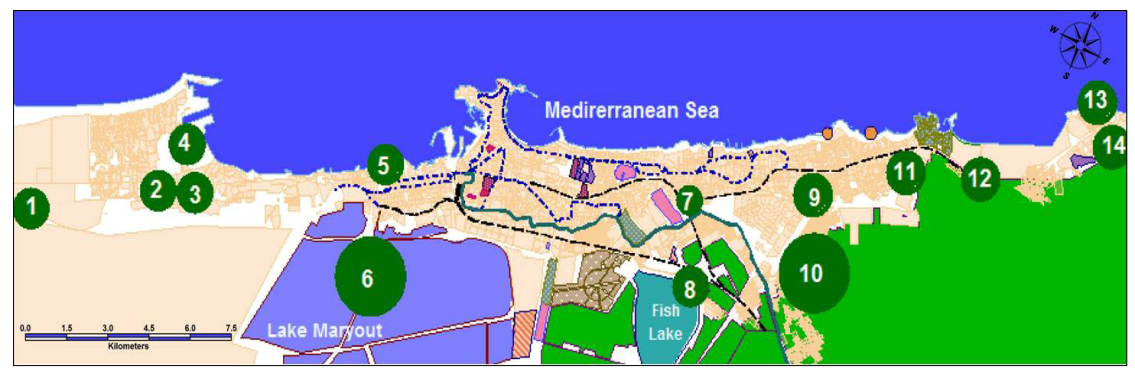

Figure 9: The proposed nodes in the eastern and western parts of Alexandria city. 


\subsubsection{Corridors' connectivity}

Following the assessment of demand areas and the potential of connectivity resources that may be utilized to create linkages between them, the actual greenway alignments are delineated. Utilizing the most suitable areas, they should link the centres with the highest demand for connectivity. Ideally, these corridors would meet the identified goals and objectives, and serve the multiple purposes of greenways. As shown in the methodology diagram, there are usually alternative ways to connect the same demanded areas; at this stage all of the possible corridor alignments should be identified. The developed concept of natural corridors as previously mentioned with the railway and tram corridors will help in forming the network; they can offer many nodes that can present alternative ways of connecting and assure the network continuity.

As a hypothetical choice, the identification of nodes was set according to their primary importance, which depended on: (a) their condensed uses, (b) their intersections with the main roads, and (c) their priorities that should be attributed with the proposed goals, fig. 10 .

\subsubsection{The pivotal role of the Mahmoudeya Canal}

The Mahmoudeya Canal gained its importance from its strategic location; it is an intermediate natural corridor that passes through Alexandria's urban fabric as a central longitudinal axis. Thus, the Mahmoudeya Canal and its nodes have a special pivotal role in forming the network. The design of all nodes aims to improve their environmental context and treat their daily issues. The proposal recommends improving public transport and cycle and pedestrian paths, and achieving sustainable development. The creation of many activities and recreation facilities, cycle and walking paths along the sides of canal will increase sustainable access to public spaces that will enhance feelings of family kinship; the following is a design proposal for one of these nodes.

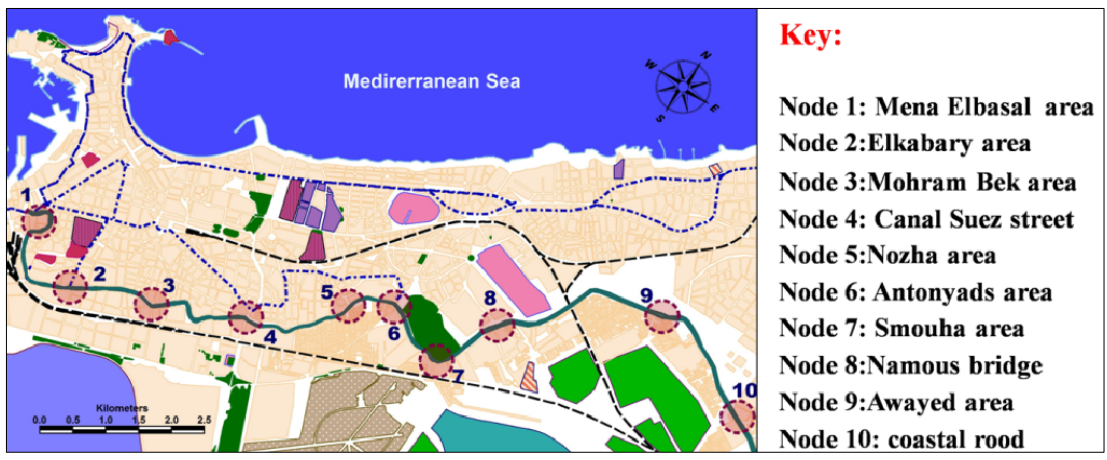

Figure 10: The proposed nodes shown, which need to be connected with the network, are along the Mahmoudeya Canal. 


\subsubsection{The proposal of a node design}

The chosen node of the Mena Elbasal area (node number 1) has a strategic location and good accessibility; it is located near Alexandria harbour and historical sites, within an old special characterized area, fig.11.

The proposed design will create opportunities to utilise spatial features to develop the adjacent area as a whole by a greenways network that connects different sites, such as the Catacombs of Kom El Shukafa, the Kom El Nadora area of Pompeus column and the Serapeum temple. The design includes a Central Plaza with a small hotel, small plaza, services and small shops that will be located at the edge of the park in front of the canal and the main entrance of Alexandria harbour. A Cultural Zone is designed to include an Open Park and an Open Theatre for the seasonal occasions that will be located at the sides of the canal to enrich the connection between the two sides of the canal, fig. 11 .

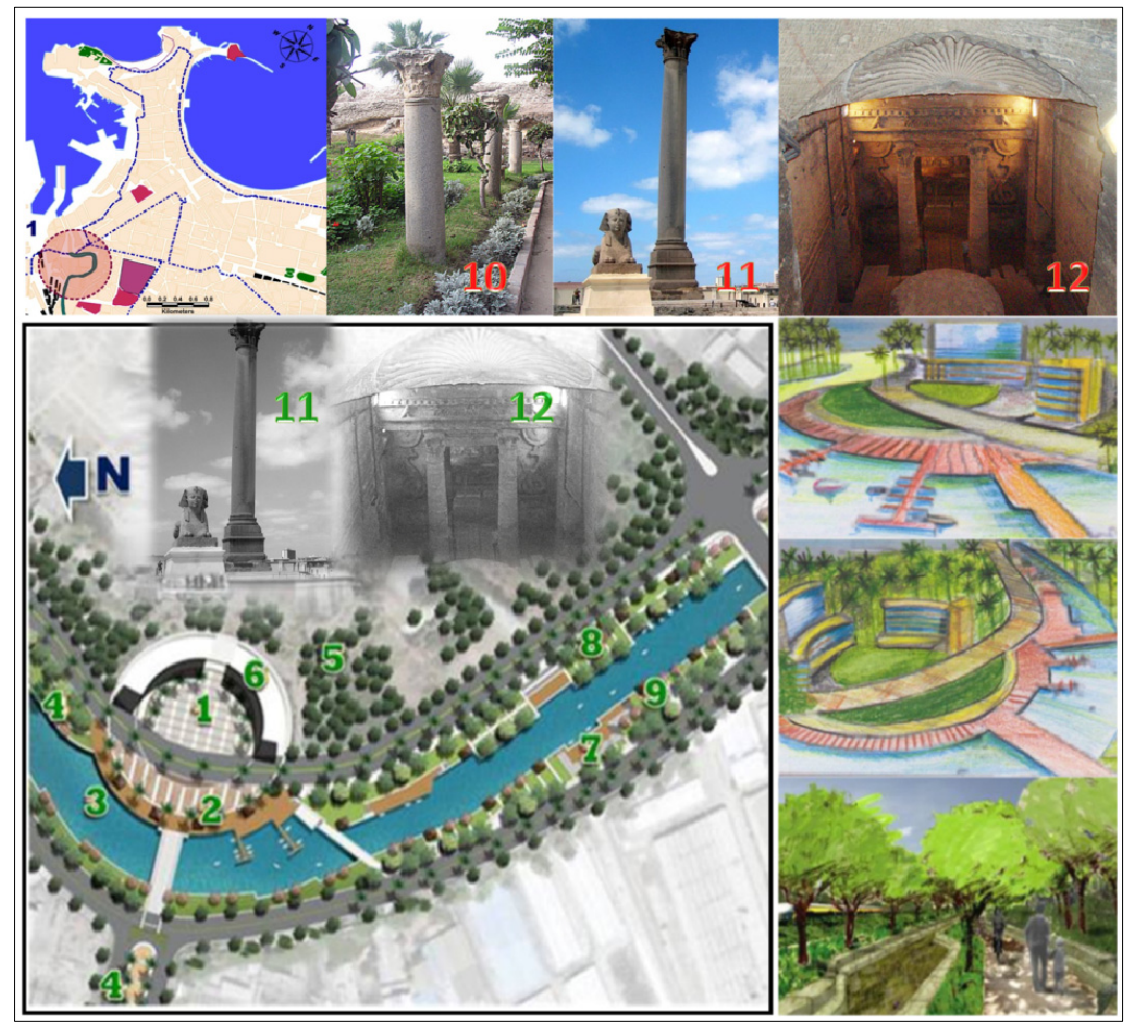

Figure 11: A prototype proposal of a chosen node along the Mahmoudeya Canal (Node no.1) includes: 1- Main plaza, 2- Marina, 3Mahmoudeya Canal, 4- Pedestrian zone, 5- Open park and recreation area, 6- Motel, 7- Open theatre, 8- Gymnasium, 9services, 10- Kom El Nadora area, 11- Pompous column, and 12the Catacombs of Kom El Shukafa. 


\section{Conclusion}

Green Corridors are particularly important in urban sustainability and they have world recognition and concern; they are a main component of ecological networks, and Egypt still suffers from deficiency of such networks on the regional level. Alexandria city, Egypt has the tools to own a high quality network of Green Corridors; it will provide opportunities close to peoples' homes for recreation, particularly walking and cycling as part of everyday routines that will improve the health and well-being of the community. The study achieved a design process for planning Green Networks and reckoned with the obtainable resources, not only natural corridors, such as the Mahmoudeya Canal, greenbelt, and waterfronts, but also there are many historical, educational and recreational areas that need to be connected. These areas should be preferred according to their priorities, for which they should be attributed to proposal goals. A multi functional network in Alexandria city, which contributes to the built environment, is required for the present communities and for new smart growth in the future. An integrated network of high quality Green Corridors will link open spaces together to help alleviate other open space deficiencies and provide opportunities for recreation and alternative means of transport.

\section{Recommendations}

This study highlights the importance of Green Corridors to urban sustainability in facing the environmental challenges in Alexandria and the effectiveness of incorporating efforts in Egypt. The following recommendations may help in achieving this aim. (1) Planning policy should aim to facilitate the delivery of an integrated network of high quality Green Corridors, linking open spaces together and providing opportunities for sustainable and alternative means of transport. (2) Incorporating the Green Corridors in the urban form of new communities and in the redevelopment of existing areas. (3) The important suggestion to policy makers is to alter the land use purposes of most plantations in project sites at all levels, thereby green areas will increase and the behaviour of citizens will improve towards sustainability. (4) Qualitative improvements of Green Corridors should be considered as environmental issues, as well as recreational needs; in addition, enhancing access to Green Corridors will emphasise the role of outdoor recreation to integrate sustainable health objectives. (5) It is necessary to establish policies for improving awareness and understanding the conservation values of the natural resources at all levels of the educational system, consequently increasing the awareness of the future generation to the importance of sustainability.

\section{References}

[1] Shochat, E., Warren P. S., Faeth, S. H., McIntyre, N. E. \& Hope, D., From patterns to emerging processes in mechanistic urban ecology, Trends in Ecology and Evolution. 21(4), pp. 186, Elsevier, 2006 
[2] Jongman, R., \& Pungetti, G., (eds). Ecological Networks and greenways, Concept, Design, Implementation Studies in Landscape Ecology, Cambridge Publications: UK, pp. 34, 38, 39, 2004

[3] Vasconcelos, P. \& Pritchard, M., A greenway for more sustainable Auckland. Proc. of the 3rd International Conference on Sustainability Engineering and Science, Auckland, NZ, 2008

[4] Little, C. E., Greenways for America, Johns Hopkins University Press: Baltimore and Maryland, pp.3-6, 1990

[5] Shafer, S. C., Scott, D. \& Mixon, J., A greenway Classification: Defining the function and Character of greenways in urban areas, Journal of Park and Recreation Administration, 18 (2), pp. 90, 2000

[6] Hellmund P.c. \& Smith D. S., Designing Greenways, Sustainable landscape for nature and people, Island Press: Washington, pp. 127-132, 215,2006

[7] Wilkie, K. \& Roach, R., Green among the Concrete, The benefits of urban nature capital, A nature capital discussion paper, Canada West, pp.4-13, 2004, Online http://www.biology.duke.edu/wilson/EcoSysServices/papers/ GreenAmongtheConcrete.pdf.

[8] Tuner, T., Greenway planning in Britain: recent work and Future plans. Landscape and urban planning, 76 (1-4), pp. 240-243, Elsevier, 2006

[9] Benedict, M.A. \& McMahon E. T., Green Infrastructure, Linking Landscape and Communities, Island Press: Washington, pp13, 37, 2006

[10] Janssen, M. A., Bodin, O., Anderies J. M., Elmqvist T., Ernstson H., McAllister R. R. J., Olsson P. \& Ryan P., Toward a Network Perspective of the Study of Resilience in Social Ecological Systems. Ecology and Society, 11(1), pp. 2-11, 2006

[11] Cities Alliance and the World Bank, Cities without Slums, Alexandria city development strategy, moving from vision to strategy and implementation. Bibliotheca Alexandria, Egypt, pp. 6-7, 2007

[12] Abdou Aziz, L.K., Analysis and Assessment of Land use Change in Alexandria, Egypt, Using Satellite Images, GIS, and Modelling Techniques. Remote Sensing \& Space Science, Egypt, 11, pp.19-23, 2008.

[13] Taylor, J., Paine, C. \& FitzGibbon J., From green Belt to greenways: four Canadian case studies. Landscape and urban planning, 23(1-3), pp. 48-59, Elsevier, 1995

[14] Alexandria, The 2000 year old Mermaid of the Mediterranean, Egypt State information service, Online http://new.sis.gov.eg/En/Story.aspx?sid=2543 